\title{
BMJ Open Systematic review of 29 self-report instruments for assessing quality of life in older adults receiving aged care services
}

\author{
Joyce Siette (1) , ${ }^{1,2}$ Gilbert Thomas Knaggs (D) , ${ }^{3}$ Yvonne Zurynski (D) , \\ Julie Ratcliffe (1) , ${ }^{4}$ Laura Dodds, ${ }^{1}$ Johanna Westbrook ${ }^{1}$
}

To cite: Siette J, Knaggs GT, Zurynski Y, et al. Systematic review of 29 self-report instruments for assessing quality of life in older adults receiving aged care services. BMJ Open 2021;11:e050892. doi:10.1136/ bmjopen-2021-050892

- Prepublication history and additional supplemental material for this paper are available online. To view these files, please visit the journal online (http://dx.doi.org/10.1136/ bmjopen-2021-050892)

Received 04 March 2021 Accepted 21 October 2021

Check for updates

(C) Author(s) (or their employer(s)) 2022. Re-use permitted under CC BY-NC. No commercial re-use. See rights and permissions. Published by BMJ.

For numbered affiliations see end of article.

Correspondence to

Dr Joyce Siette;

joyce.siette@mq.edu.au

\section{ABSTRACT}

Background Quality of life (QoL) outcomes are used to monitor quality of care for older adults accessing aged care services, yet it remains unclear which QoL instruments best meet older adults', providers' and policymakers' needs. This review aimed to (1) identify QoL instruments used in aged care and describe them in terms of QoL domains measured and logistical details; (2) summarise in which aged care settings the instruments have been used and (3) discuss factors to consider in deciding on the suitability of QoL instruments for use in aged care services.

Design Systematic review.

Data sources MEDLINE, EMBASE, PsycINFO, Cochrane Library and CINAHL from inception to 2021.

Eligibility criteria Instruments were included if they were designed for adults ( $>18$ years), available in English, been applied in a peer-reviewed research study examining QoL outcomes in adults $>65$ years accessing aged care (including home/social care, residential/long-term care) and had reported psychometrics.

Data extraction and synthesis Two researchers independently reviewed the measures and extracted the data. Data synthesis was performed via narrative review of eligible instruments.

Results 292 articles reporting on $29 \mathrm{QoL}$ instruments were included. Eight domains of QoL were addressed: physical health, mental health, emotional state, social connection, environment, autonomy and overall QoL. The period between 1990 and 2000 produced the greatest number of newly developed instruments. The EuroQoL-5 Dimensions (EQ-5D) and Short Form-series were used across multiple aged care contexts including home and residential care. More recent instruments (eg, ICEpop CAPability measure for Older people (ICECAP-0) and Adult Social Care Outcomes Toolkit (ASCOT)) tend to capture emotional sentiment towards personal circumstances and higher order care needs, in comparison with more established instruments (eg, EQ-5D) which are largely focused on health status.

Conclusions A comprehensive list of QoL instruments and their characteristics is provided to inform instrument choice for use in research or for care quality assurance in aged care settings, depending on needs and interests of users.

\section{STRENGTHS AND LIMITATIONS OF THIS STUDY}

$\Rightarrow$ Compared with the largest review of the topic to date, the current review contains an additional 16 quality of life instruments and provides a structured index of domains.

$\Rightarrow$ This review provides the first quantified demonstration of how self-reported measures of quality of life have developed over the past 40 years and the aged care setting where these instruments have been used.

$\Rightarrow$ Our review only included instruments applied to populations of older adults accessing aged care services.

$\Rightarrow$ Our review identifies current quality of life instruments used in aged care settings internationally and represents a first step in supporting choice of suitable instruments to be used for monitoring and evaluating quality of care in aged care service settings.

\section{INTRODUCTION}

Globally, the demand for aged care services has increased. ${ }^{1}$ Aged care services are designed to support older adults who require assistance to maintain independence for as long as possible (also known as home aged care, community aged care, social care) as well as supporting older adults who can no longer live at home (also known as assisted living facilities, long-term care (LTC), nursing homes, care homes or residential aged care). As the accountability of aged care services becomes increasingly important globally, ${ }^{12}$ there is a need to establish longterm and comprehensive measures of aged care service quality. Measures need to be easily operationalisable and capable of capturing information reflective of public expectations for high-quality, person-centred aged care services. One way to determine the quality and person-centredness of aged care services is to assess care outcomes which are 
important to clients and which are achieved at the client level.

Of aged care quality indicators used globally, recipient quality of life (QoL) outcomes are among the most highly valued and meaningful by aged care consumers and families. ${ }^{3}{ }^{4}$ QoL is broadly defined as an individual's perception of their physical health, psychological state, social relationships and environmental context. ${ }^{5}$ Despite the significance of QoL outcomes to aged care clients, and despite extensive development and experimentation with quality measures in aged care settings (eg, pressure injuries, falls, use of physical restraints, medication errors, involuntary weight loss), internationally, the collection of QoL outcomes is limited, ${ }^{6}$ however, more recent efforts on how QoL in aged care should be defined is emerging. ${ }^{7}$

Fundamental to the challenge of measuring QoL is selecting an instrument for use from the large variety of available QoL instruments. Despite the continued development of new instruments, no universally accepted measure has emerged, in part because there are no agreed conceptual criteria on what an instrument should contain, and no single measure can suit every purpose or application. Dimensions of QoL prioritised for measurement also vary across disciplines, ${ }^{8}$ and new instruments are regularly being developed to reflect new and more niche perspectives about factors of life quality. ${ }^{9}$ Despite efforts by the Organisation for Economic Co-operation and Development (OECD) to formalise the measurement of QoL, advice on how researchers can effectively use available instruments is lacking. ${ }^{6}$ Researchers and aged care providers who wish to measure QoL in older adults receiving care in home and residential settings tend to select instruments based on what is familiar to them within their discipline or organisation, what is most often used by others, or they create ad hoc purpose-built, non-standardised instruments. ${ }^{10}$

Despite the problems and barriers intrinsic to the collection of QoL outcomes, several countries have incorporated existing QoL measures into routine aged care evaluation and reporting practices. ${ }^{10}{ }^{11}$ In Iceland and Canada, QoL scores of aged care residents are derived from data about the use of physical restraints, behavioural symptoms, among other objective measures. ${ }^{11}{ }^{12}$ However, such measures do not provide insight into the experience of care, and therefore, do not necessarily correlate with the subjective experiences of clients. For example, a recent Australian study found no significant correlation between client care satisfaction and the use of physical restraints in aged care settings. ${ }^{13}$

Elsewhere, subjective client-reported measures are used alongside traditional objective indicators of QoL (ie, medication use, health status, mobility, pressure injuries). For example, departments of health in the UK, Denmark, Austria, Finland and the Netherlands routinely collect QoL outcomes using versions of the Adult Social Care Outcomes Toolkit (ASCOT), ${ }^{14}$ a QoL questionnaire which captures emotional and subjective sentiment towards personal circumstances and levels of satisfaction regarding care needs. ${ }^{15}$

In Australia, improving the QoL of aged care clients has been a stated policy objective for the last decade. In 2019, a new set of Aged Care Quality Standards which are applicable to aged care providers across all aged care settings were introduced, ${ }^{16}$ which state care providers should take steps to continuously improve client QoL. However, to date, no questionnaires or standardised measures to track client QoL have been mandated for use in Australia, although latest commissioned reports recommend universal QoL reporting in aged care. ${ }^{17}$ Recent reports of mistreatment and abuse of Australian aged care recipients underscore the need for standardised, comparable QoL measures. ${ }^{18}$

Previous reviews on QoL instruments have focused on their psychometric properties such as validity and reliability, ${ }^{19} 20$ with one review providing a comprehensive analysis of how instrument contents differ. ${ }^{21}$ However, these reviews are directed at younger adults $(<65$ years of age), do not describe how the instruments have been used within the aged care context, and review a limited set of instruments and instrument properties. Another review with aims matching our own is based on outdated evidence. ${ }^{22}$

A comprehensive review of current validated and implemented instruments that measure QoL both objectively and subjectively is needed to support the choice of instruments that are fit for purpose in aged care settings. In our review, our objective is to inform researchers, aged care practitioners and managers about the breadth, variety, and content of available measures of QoL that have been successfully applied in aged care settings. Specifically, we aimed to (1) identify QoL instruments used in aged care and describe them in terms of QoL domains measured and logistical details; (2) summarise in which aged care settings the instruments have been used and (3) discuss factors to consider in deciding on the suitability of QoL instruments for use in aged care services.

\section{METHODS}

\section{Search strategy}

Studies were included in this review if they (1) contained the term 'quality of life', (2) studied and described an aged care population and (3) administered a standardised QoL instrument (ie, verbal QoL questionnaire or QoL self-assessment survey) on study participants, (4) represented original peerreviewed articles and were not a systematic review or a conference proceeding. Search terms were therefore a combination of QoL assessment and older persons descriptors in aged care (ie, (QoL OR assessment) AND (older adults OR elder*) AND (care homes OR nursing homes OR residential aged care OR community care OR social care OR home-based care)). Articles were retrieved from the databases PsycINFO, PubMed, Cochrane, CINAHL and Embase from the 
earliest records until 29 January 2021 and included studies focusing on implementation or routine care. See online supplemental file for further information.

Studies were also identified through citations from relevant literature reviews focusing on QoL in older adults and checking reference lists of the included articles.

\section{Study selection, data extraction and analysis}

Database search results were exported into a reference citation manager. A random selection of $25 \%$ of the abstracts was screened by the research team. Inter-reviewer agreement was $90 \%$, with disagreement on the inclusion of one paper, which was brought to the larger research team. Selected full-text articles were then obtained for the final screening. Final study selection was completed by two independent authors (JS and GTK) with a third author (JW) helping to resolve disagreements. Studies were excluded if: (1) study population had a mean age lower than 65 ; (2) if $<50 \%$ of the study population was not accessing aged care services (eg, home/social care or residential/LTC); (3) the study was not peer-reviewed and did not improve primary research (eg, systematic reviews and conference proceedings); (4) study did not directly measure QoL and (5) only a portion of the instrument was described. Instruments were excluded if they were designed for children or adolescents or not a standardised instrument (ie, newly designed questionnaires for the purposes of a study without validated psychometric properties).

A purpose-designed data collection form on Excel workbook was tested and then used to capture qualitative and quantitative data and other relevant details of the included studies. Once an initial extraction of study details was complete, an evaluation of the identified QoL instruments was carried out. Information on the instrument properties was extracted, including: (1) domain measured; (2) administration details and (3) context of instrument application. Additional instrument details included mode of administration (eg, in person, on-line, paper form), the settings in which the instruments had been used, socio-demographic details of respondents, number of items, length of instrument, number of translations and versions, target population, required cost and any necessity for training. These details were principally extracted to gauge feasibility of applying the instrument in aged care settings. In addition, study-specific details were extracted including sample size, study design and setting (aged care service type, country where performed). Efforts were made to contact study authors for original QoL instruments.

\section{Thematic analysis}

Identified instruments were analysed using a thematic analysis approach. ${ }^{23}$ Facets of QoL (ie, health status, lived environment, social interaction levels) addressed by identified instruments were coded under domain categories. The review team (JS and GTK) examined the full set of instrument item domains, and combined domains under common headings when domains between instruments were indistinguishable or significantly associated. For example, question items such 'depression levels' and 'depression diagnosis' were clustered around the theme 'psychological health'. Coding was undertaken by two reviewers (JS and GTK) and any discrepancies that arose were solved through discussion with the third member of the review team $(\mathrm{JW})$. Themes were gradually assembled into larger similar domains. Once these domains were reviewed and amended by the review team, they were further refined and defined. In addition to instrument domains, the target populations of instruments were also recorded. It was anticipated that domains might overlap and that instrument items could conceivably be categorised across several domains; however, the categories provided by this technique afforded some order to the otherwise unmanageably large range of domains authors attributed to developed instruments. The review team included academics with backgrounds in psychology and aged care (JS), sociology (GTK), health economics and psychometrics (JR) and epidemiology/public health (JW), helping to minimise disciplinary biases. Results were synthesised as a narrative review.

\section{Patient and public involvement}

No patient involved.

\section{RESULTS \\ Identification of instruments}

The PRISMA diagram summarises the search results, screening and reasons for exclusion of studies (figure 1). The database search produced an initial 2612 records of which 292 articles reporting on 29 QoL instruments were included. Table 1 and online supplemental file contain details on the instruments included in the final review. The instruments are either: (1) the original instruments if no revised version was found or (2) the latest revised version. A breakdown of when the instruments were first developed can be found in figure 2 .

\section{Instrument domains}

The identified QoL instruments were designed for use with three distinct populations groups (adults, older adults and adults living with dementia), and covered nine QoL domains in their assessment (table 1). Thirteen instruments were designed for use with adults generally, 10 were designed for use with older adults and 7 were designed for adults living with dementia.

Instrument developers often associated instruments with specific domains. However, there was no clear consensus regarding domains classification and definition. Consequently, we amalgamated similar domains between instruments under common domain definitions developed for this review. Based on a recent exhaustive systematic review of older people's understandings of QoL, we further adjusted and expanded on domains 


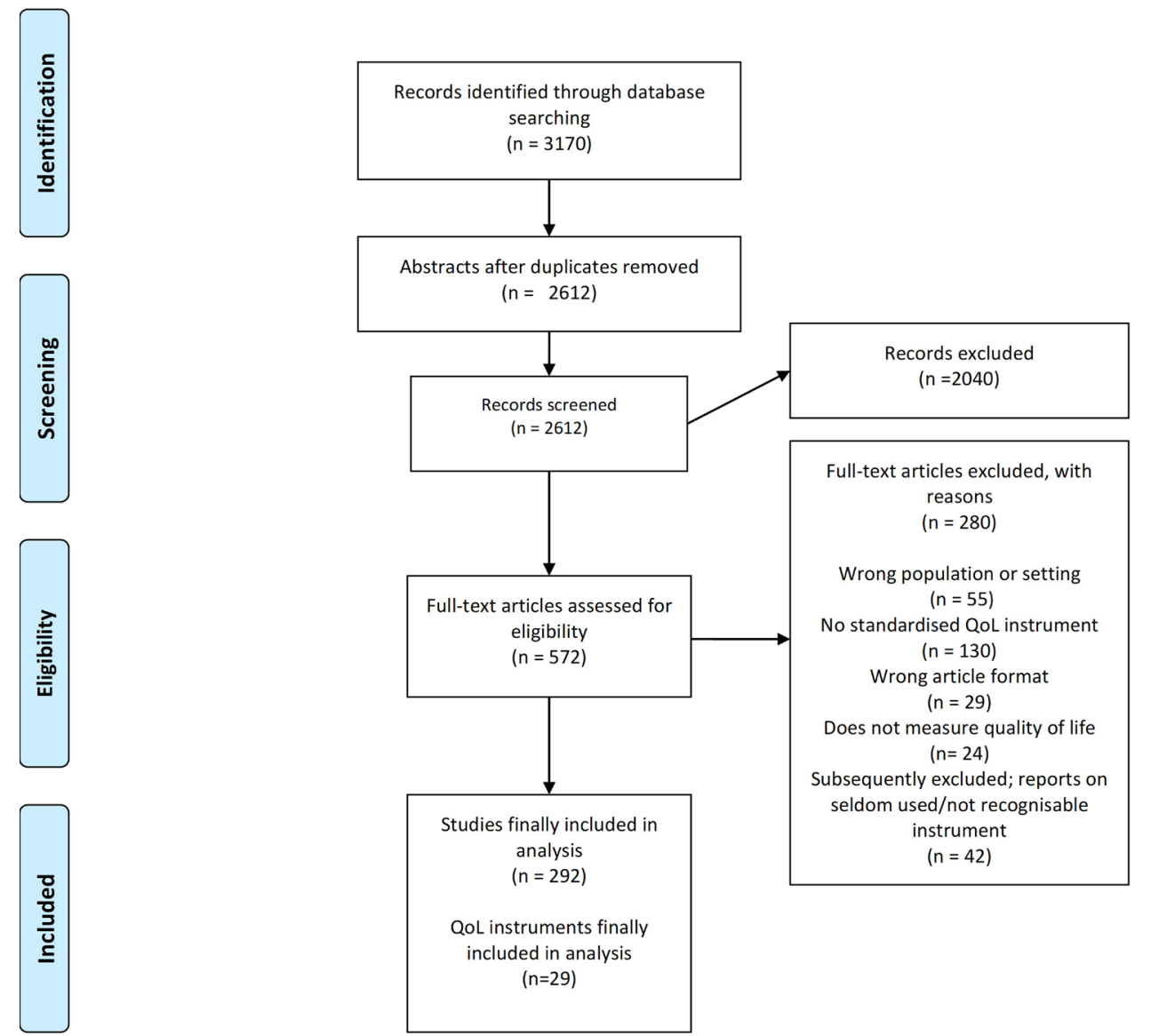

Figure 1 PRISMA diagram. PRISMA, Preferred Reporting Items for Systematic Reviews and Meta-Analyses; QoL, quality of life.

identified in this review to incorporate aspects of QoL which are important to older people in OECD countries. ${ }^{24}$

The final nine instrument domains were: physical health, mental health, emotional state, social connection, environment, personhood, autonomy, spiritual connection and overall QoL.

Physical health refers to instrument items that addressed functional status, physical conditions and their related symptoms, pain, and perceptions of overall health. Mental health refers to items that capture mental and cognitive health conditions, as well as clinical symptoms that would indicate mental health problems. Emotional state refers to items which capture experiences of positive and negative emotions which are not obviously symptoms of mental health. This includes items which explore feelings of peace, calm, happiness and loneliness, among others.

Two domains identified relate to external circumstance and resources. Social connection refers to items addressing the frequency and quality of social interactions. Items addressing feelings of belonging, friendship and support were also categorised under this domain. Environment refers to items addressing living conditions and deployable resources. Included in this domain are items addressing satisfaction with social care services as well as items which ask respondents to reflect on the emotional, psychological and physical effects of living conditions.

Three domains related to existential beliefs and concerns of respondents. The domain personhood relates to items addressing levels of satisfaction with personally and culturally meaningful activities which provide joy and a sense of identity. This domain also refers to items that address identity continuity, and effects of ageing on identity and sense of self. Autonomy relates to items addressing capacity and satisfaction with one's ability to manage activities of daily living. Emotion-centric items associated with dependence and autonomy are also categorised as relating to autonomy. Finally, the domain spiritual connection covers feelings of faith, and inner peace, as well as involvement in religious or spiritual practices like prayer. We also included an overall $Q o L$ theme, relating to single items asking respondents to rate their QoL as a whole.

Domains were often inter-related and multiple items were categorised across multiple domains. 'Emotional state', examined by 26 instruments, was the most frequently included theme. This was followed by 'social connection', examined by 24 instruments $(82.3 \%)$, and 'physical health' which was examined by 19 instruments $(65.5 \%)$. Although spiritual connection is significant to the QoL of many older adults, ${ }^{24}$ only one instrument, the JoLS, examined this domain. Of the instruments 


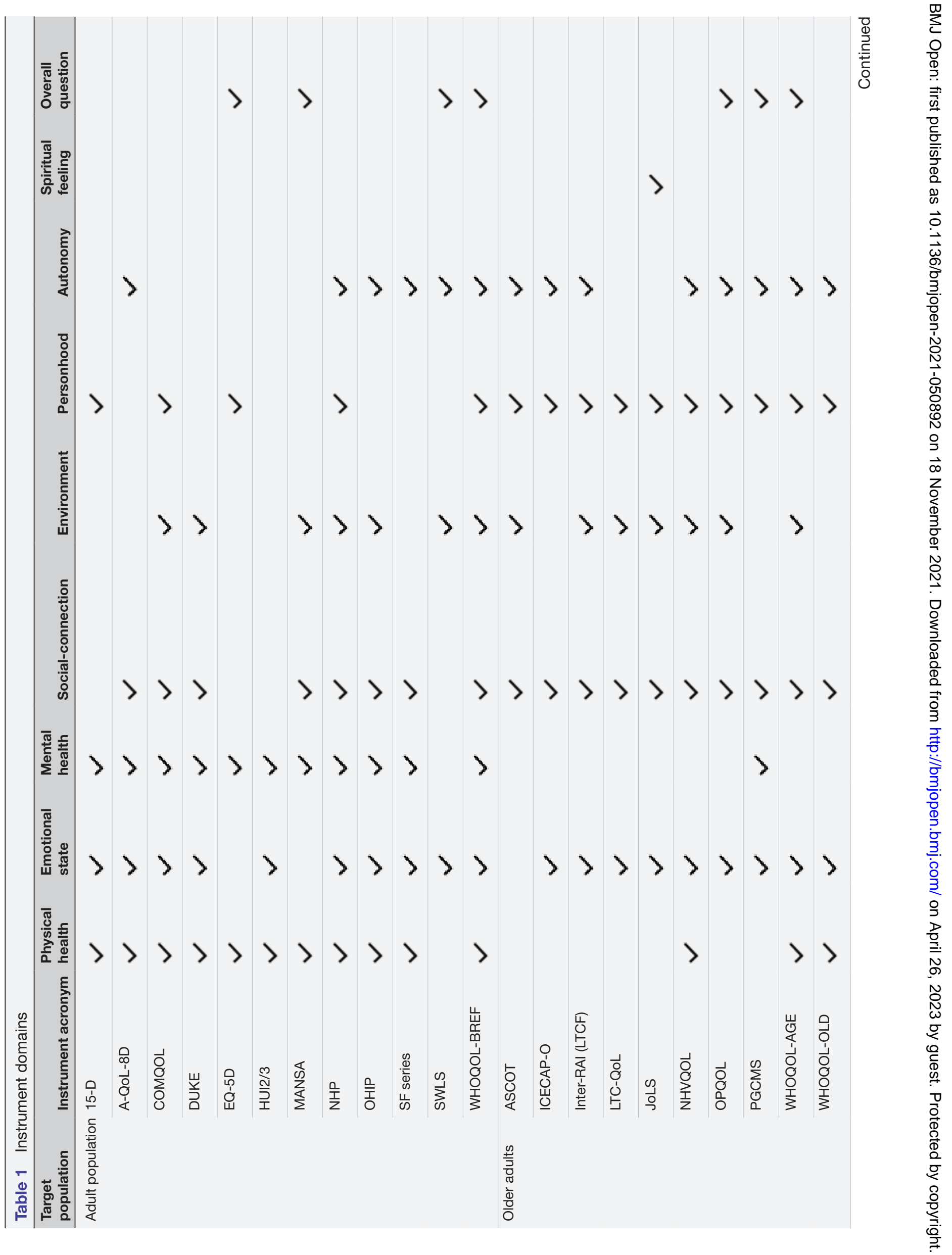




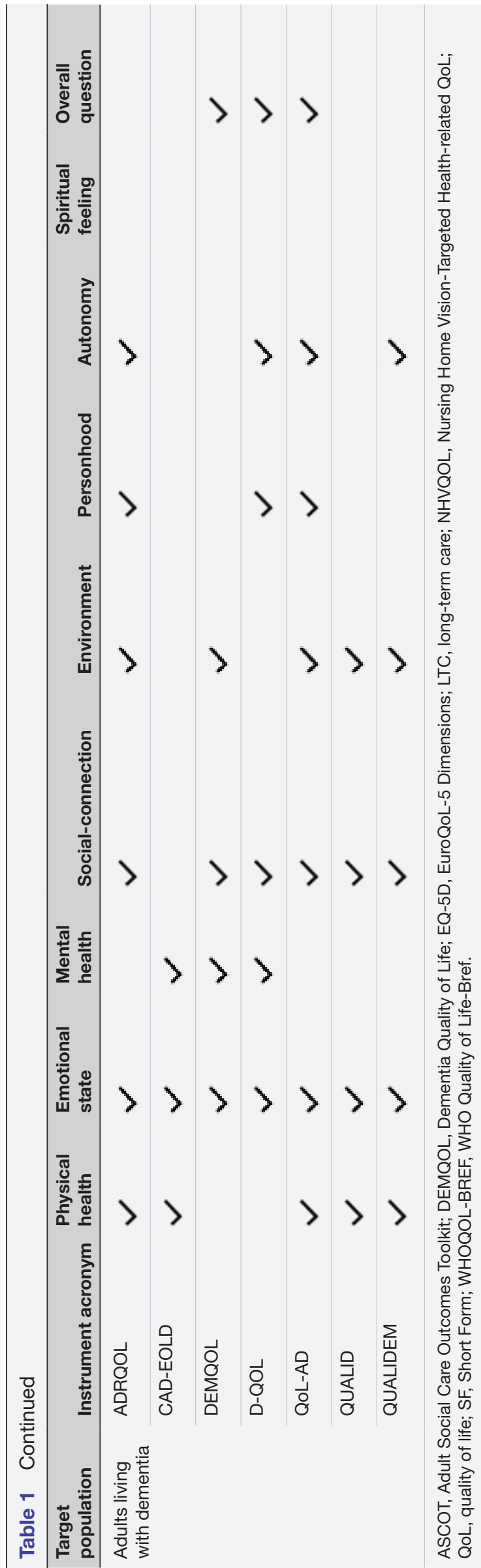

analysed, the WHO Quality of Life-Bref (WHOQOLBREF) covered the largest range of domains. Overall, the instruments commonly captured objective and subjective concepts of the quantity or length of life and QoL, which varied between individuals' health status and their ability to achieve physical, mental and social well-being.

Features of QOL instruments

All instruments contained multiple items, smallest being five items (ICEpop CAPability measure for Older people, ICECAP-O) and the largest containing 57 items (Nursing Home Vision-Targeted Health-related QoL, NHVQOL). However, some instruments were comprised of items which were abstract and/or difficult to answer, meaning the number of items did not uniformly determine expected completion times. Estimated completion times ranged from 1 to $3 \mathrm{~min}$ (Short Form-8, SF-8) to 40-60 min (Inter-RAI-LTC).

The fewest response options were found within simple yes/no questionnaires (ie, Philadelphia Centre Geriatric Moral Scale, PGCMS), while other instruments offered response options along a unipolar scale (ie, EuroQoL-5 Dimensions-5-level, EQ-5D-5L). Half of the instruments used five-point or four-point unipolar Likert scales $(14 / 29,48.3 \%)$. Items asked individuals about the frequency, intensity, strength of agreement or truth of specific and non-specific thoughts, feelings, experiences and statements. Instruments were named after academic affiliation $(3 / 29,10.3 \%)$ as with the Duke Health Profile (DUKE) and organisational affiliation (5/29, 17.2\%) as with the World Health Organization Quality of Life (WHOQOL) instruments. However, for the majority of cases $(21 / 29,72.4 \%)$, instruments were named after their key concept or approach. For example, all of the instruments designed for adults living with dementia referenced this target population in their titles.

Furthermore, most instruments were developed with a theoretical influence ${ }^{1525-45}(20 / 29,69.0 \%)$, with the WHO definition of QoL ('an individual's perception of their position in life in the context of the culture and value systems in which they live and in relation to their goals, expectations, standards and concerns') most frequently reported $(8 / 21,38.1 \%)$. Other theories included the capabilities approach, ${ }^{47-51}$ Seligman's and Keye's well-being theory, ${ }^{52-56}$ salutogenesis framework, ${ }^{52}$ Lehman's conceptualisation of QoL, ${ }^{57}$ gap theory ${ }^{58-60}$ and adaptation-coping model..$^{61} 62$

Dementia-specific instruments were based on theories such as the Kitwood's Dementia Care Mapping Approach $^{63}$ and the Lawton model, ${ }^{64}$ which proposes a conceptual understanding of the relationship between domains of health-related QoL and other areas of impact for individuals with dementia. Other disease-state specific instruments (eg, oral health) was developed using Locker's conceptual model of oral health ${ }^{65}$ and the WHO's International Classification of Impairments, Disabilities and Handicaps. ${ }^{66}$ One instrument (Health Utility Index, HUI) applied the von Neumann-Morganstern utility 


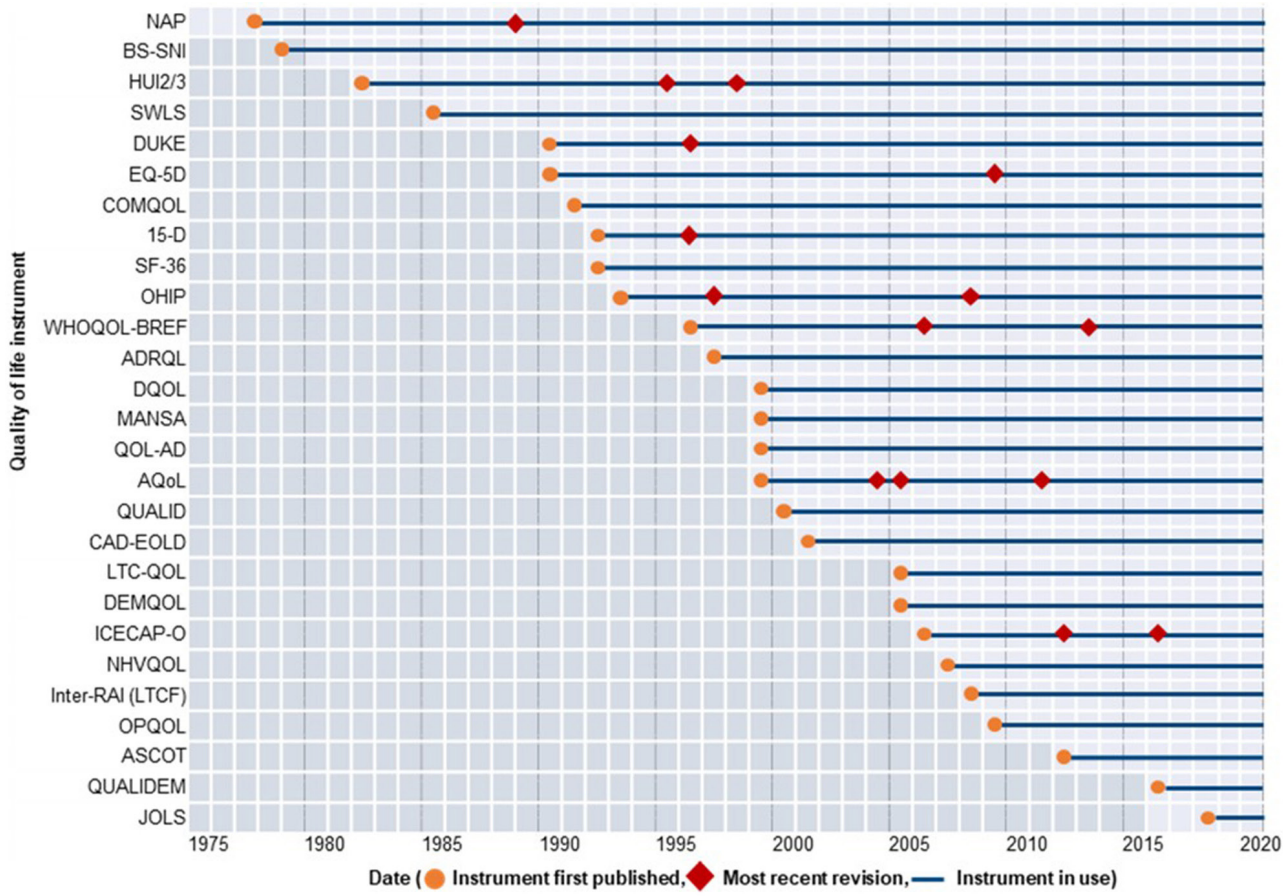

Figure 2 Historical development of quality of life instruments for older adults. ASCOT, Adult Social Care Outcomes Toolkit; EQ-5D, EuroQoL-5 Dimensions; SF-36, Short Form 36; QOL, quality of life.

theory ${ }^{47}$ and the multiattribute framework, ${ }^{3367}$ however, these frameworks were not related to QoL and were more focused on economics more generally.

It was unclear if the more commonly used instruments (eg, SF series, EQ-5D, and interRAI-LTC) were developed using a theoretical approach, however the development for these standardised, non-disease-specific instruments were conducted using a rigorous, reiterative approach to describe and value health states (eg, EQ-5D was developed from 14 members in 5 different countries, SF series from the Medical Outcomes Study Approach). Furthermore, more recent instruments (eg, ICECAP-O) were developed from the ground up using qualitative research to define their QoL conceptual attributes (eg, capability) rather than as an overarching theoretical approach.

Table 2 presents a comparison of the logistical factors associated with instrument use. Of the 29 instruments identified, 12 were designed for self-completion, 14 were intended to be administered via interview and 3 were designed for completion via proxy or via interview with a carer. Some instruments, such as the ASCOT, are currently available in interview, self-completion and proxy versions. ${ }^{15}$

The SF series and the EQ-5D instruments were relatively short and simple to administer. Both instruments are short, contain simple, straightforward question items, are readily and freely available, have dedicated websites which offer user support, are accompanied by detailed user manuals, have been translated into a variety of languages, and can be administered by either interview or self-completion.

The extent of instrument translation varied. Some instruments were available in English only (eg, Comprehensive
Quality of Life Scale (COMQOL), Nursing Home Visionrelated Quality Of Life (NHVRQOL) and Long Term Care Quality Of Life assessment scale (LTC-QOL)), while others were available in up to 32 languages (eg, 15-D, WHOQOL-BREF), and 180 languages (eg, EQ-5D) other than English.

Table 2 further provides available information about the psychometric properties of the instruments. Reliability and validity metrics for older adult populations were searched for each included instrument and summarised according to the the COnsensus-based Standards for the selection of health status Measurement INstruments (COSMIN) taxonomy. ${ }^{68}$ All instruments were tested for both reliability and validity with the majority of instruments having good validity $(16 / 21,76.2 \%)$ and validity $(16 / 21,76.2 \%)$. There were 10 instruments $(47.6 \%)$ that had been tested for responsiveness, with ASCOT-SCT4, ICECAP-O and EQ-5D able to adequately detect clinically important interventional changes.

\section{Development of the instruments over time}

Almost half of the instruments we identified had been first developed in between 1990 and 1999. As shown in figure 2, the oldest instrument was developed in 1975 (Philadelphia Geriatric Centre Moral Scale, PGCMS), while the newest instrument was developed in 2018 (Joyof-Life Scale, JoLS). Since 2000, 13 instruments have been designed. The 1990s saw the development of eleven new instruments.

Many of the newer measures contained fewer items or were accompanied by SF versions. Further, over the past 15 years, there have been significant efforts to move towards questionnaires that focused more on social 


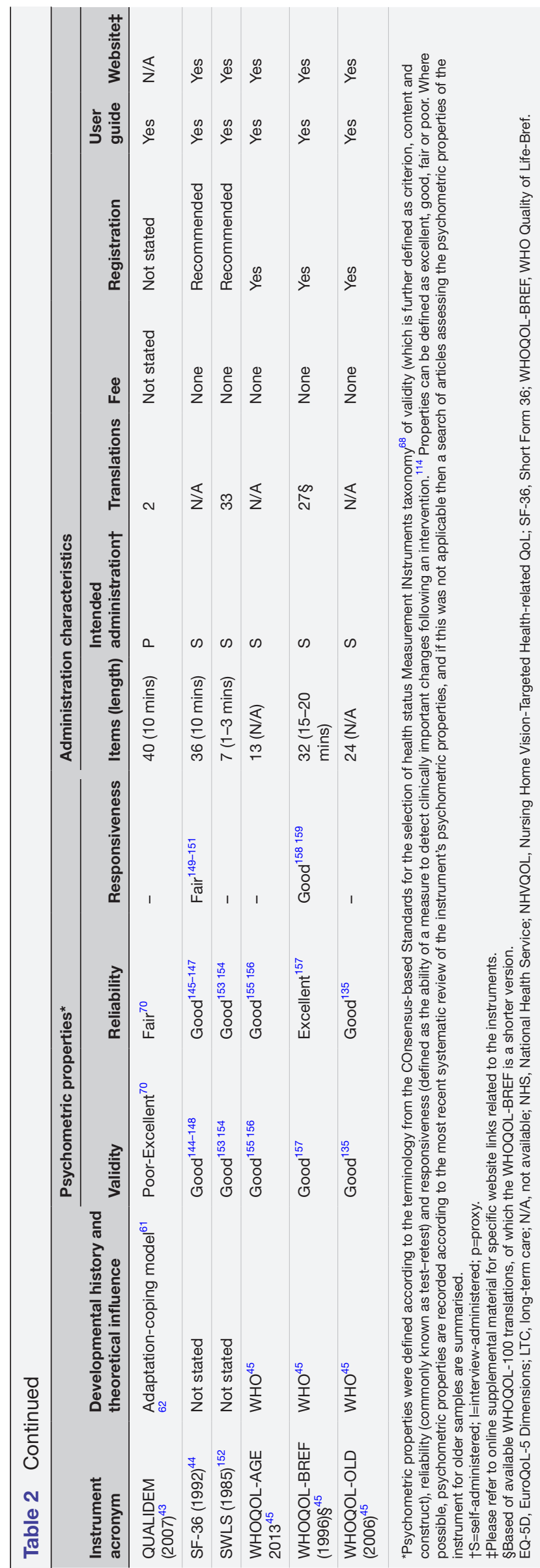

health, care and participation. Examples of these instruments include the Quality of Life In Late-Stage Dementia (QUALID, 2000), the ICECAP-O (2006) and the ASCOT (2012). Finally, instruments that were purpose built for older people have become more prevalent, although the oldest instrument identified was designed for older people initially in 1975 (PGCMS). The 1990s in particular produced a significant influx of instruments designed for older adults and for adults living with dementia.

\section{Application context}

Table 3 presents a summary of the six contexts in which the selected articles have used the QoL instruments. These contexts included: home care (ie, services offered at home and in the community to support independent living, also known as community-aged care, social care), support centre (ie, a place which provides care and/or recreational opportunities and facilities for older adults who cannot be fully independent. These include but are not limited to senior centres and adult day centres), residential aged care (ie, a place that provides older adults with accommodation and personal care, as well as access to nursing and general healthcare services, and are commonly known as nursing homes, LTC, care homes or residential aged care facilities), associated living group facilities (ie, primarily provides personal care in a home-like, social and group setting, for instance group living homes, supportive housing units, other special accommodations), training facilities (ie, places that offer improvement in a particular area, such as cognitive training facilities, off-site training facilities, exercise clinic or memory clinic), and primary care (ie, healthcare provided in the community for older adults).

Some instruments were used in one or a few studies and across a limited sample of older people (eg, COMQOL, DUKE, Oral Health Impact Profile (OHIP)), while others were used extensively across study types, countries and aged care settings (eg, EQ-5D, QOL-AD, SF series). The latter have also been used in range of study designs such as randomised control trails, quasi-experimental and observational studies.

The SF series (SF-36, SF-12 and SF-8) was the most rigorously adopted instrument used to assess QoL in aged care settings (76 studies), followed by the EQ-5D (49 studies) (see table 3). The HUI2/3 was applied to the greatest number of older adults $(\mathrm{N}=572411)$, followed by the inter-RAI $(\mathrm{N}=566$ 885) and the ASCOT $(\mathrm{N}=32$ 433). Despite the ASCOT being the third most recently developed instrument (developed in 2012), it has been used in large cohort studies assessing over 30000 older adults. The EQ-5D and the SF-36 were the most widely applied instruments across settings (eg, senior centres, clinics, assisted living facilities and residential aged care facilities).

Generic preference-based instruments were further identified and include the ASCOT, SF-6D, EQ-5D ${ }^{69}$ measures which incorporate weighted scoring algorithms based on the preferences of general population sample 


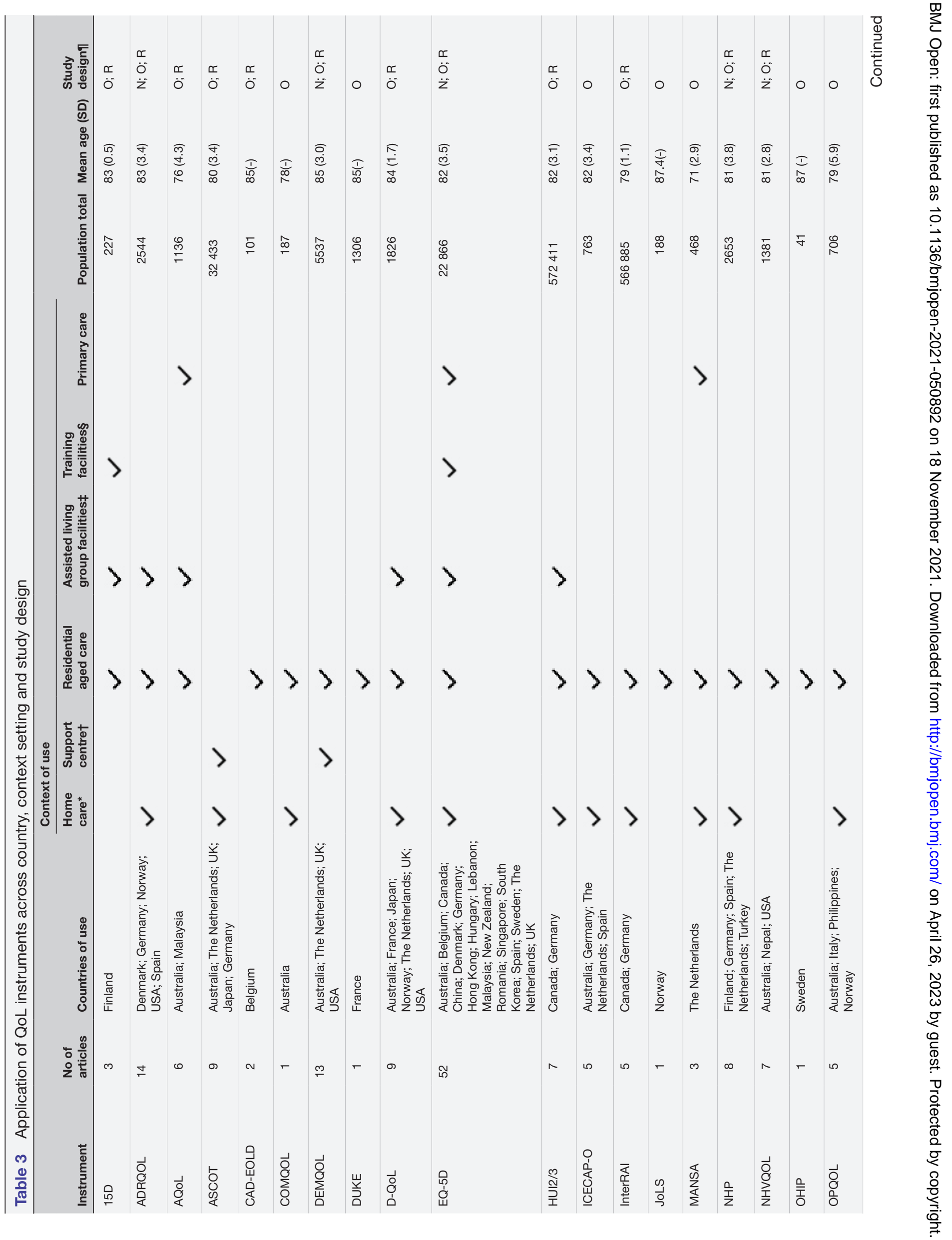




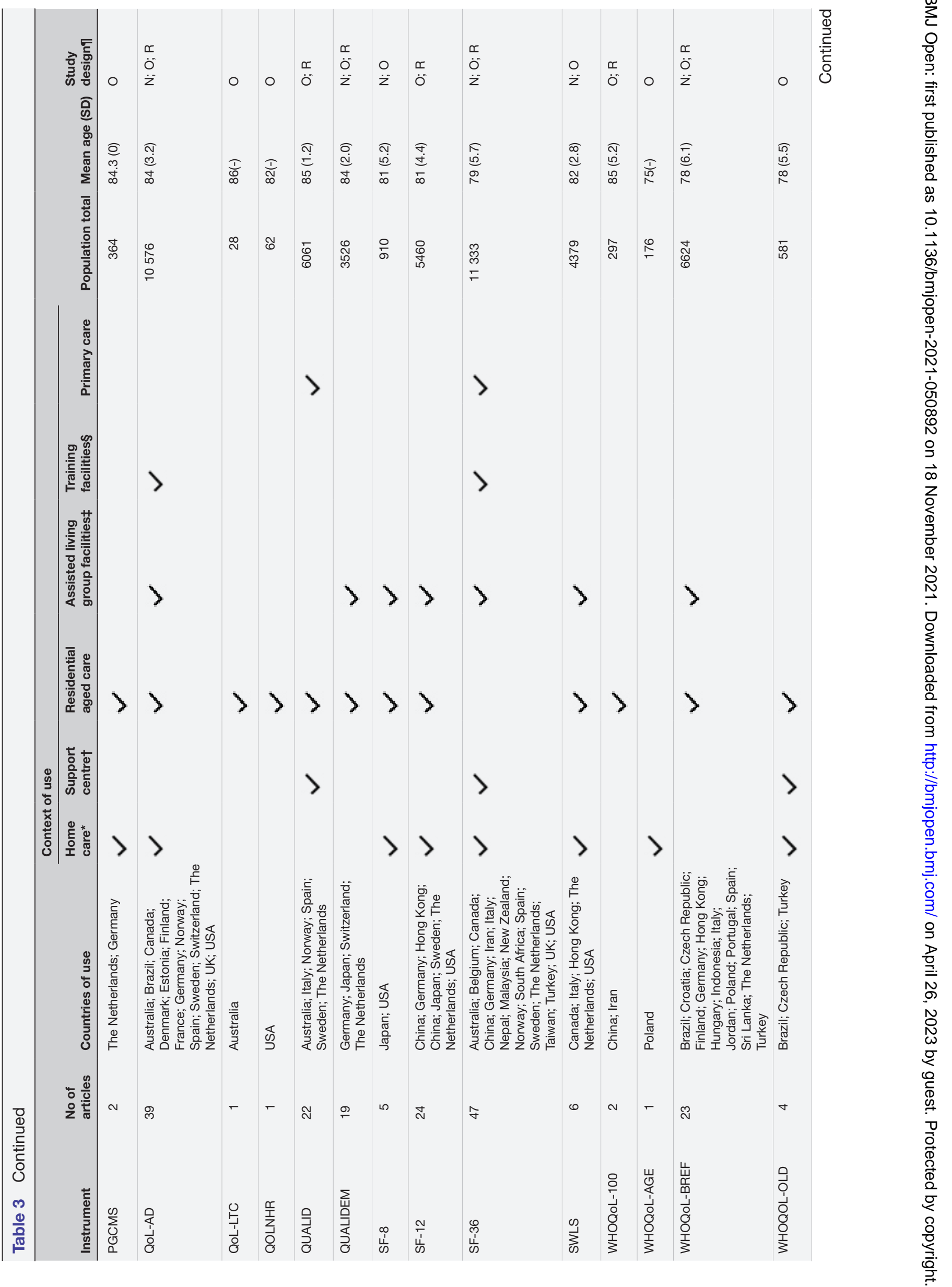




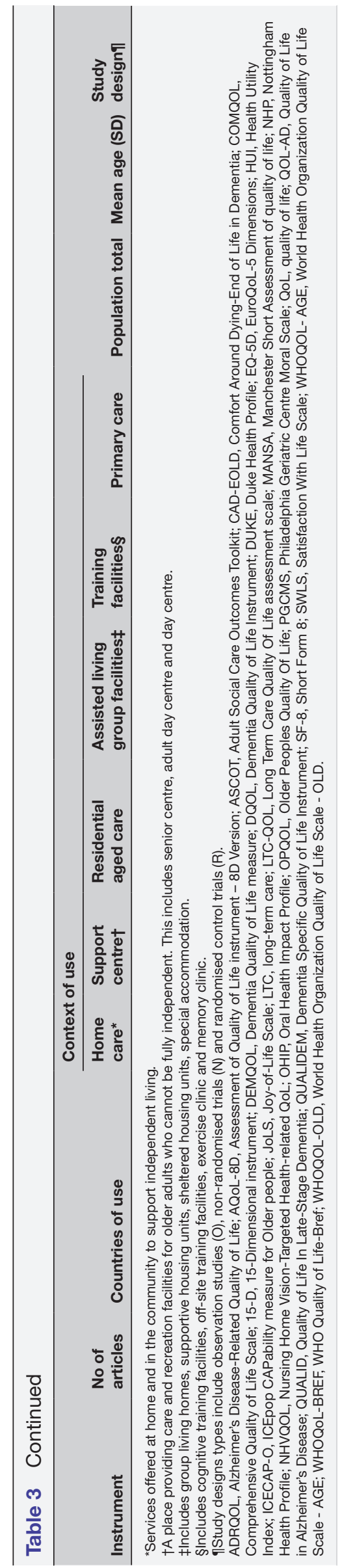

and are therefore amenable for economic evaluation in addition to quality assessment. Generic non-preferencebased instruments (eg, WHOQoL-Bref, OPQOL) were also recognised and are not suitable for economic evaluation but can be suitable for quality assessment.

\section{DISCUSSION}

This review provides a comprehensive examination of standardised QoL instruments and how they have been used in aged care settings over time. We identified 293 studies reporting on 29 instruments which have been used to gauge older adults' QoL in multiple aged care settings. In the last decade, QoL instruments have tended to highlight emotional and subjective needs of the older adult's personal circumstances, compared with earlier instruments that were fixated on older adults' physical health condition.

Although previous reviews have reported on the use of QoL instruments in aged care settings, knowledge of how QoL measures have been applied in aged care settings is incomplete. Existing reviews have focused on condition-specific instruments, such as those suitable for adults living with dementia ${ }^{70}$ or hip fractures, ${ }^{71}$ or on analysing particular instrument properties, such as suitability for economic analysis. ${ }^{69} 7273$ We found one recent review with aims similar to our own, however, that review focused on and was restricted to instruments which had undergone feasibility testing in aged care environments, and identified only 13 instruments. ${ }^{20}$ Furthermore, the review did not consider instrument feasibility (ie, time to administer) or the contexts of instrument application (ie, number and type of respondents), ${ }^{20}$ which is useful information on how instruments can be used for specific purposes, such as for research or for care quality assurance in aged care settings.

Our review enriches current knowledge by providing a broad and inclusive analysis of the characteristics of QoL instruments used across multiple contexts in which aged care is delivered. Similar to Garratt $e t a l,{ }^{59}$ we found a significant increase in the production of instruments designed for older people and/or adults living with dementia over time; all identified instruments designed after 2000 were population specific (eg, age, neurological condition). We also identified a degree of convergence over time towards greater coverage of subjective and person-centred conceptualisations of life quality, and a decrease in focus on physical health. Five out of the nine instruments designed after 2005 did not equate poorer physical health and limited capacity for independence as an indication of reduced life quality. Rather, instruments such as the ASCOT or ICECAP-O tended to capture emotional and subjective sentiment towards personal circumstances and levels of satisfaction regarding current physical health and higher-order needs (ie, companionship, dignity, love). This convergence has largely been a result of recent policy reform in the UK and Western 
Europe, which has sought to ensure that the higher-order needs of aged care recipients are accommodated. ${ }^{35} 7475$

Several factors will inform the suitability of identified instruments for use in aged care settings. Decisions about instrument suitability will need to take into account the extent of instrument alignment with current evidence on older adults' QoL; logistical factors involved with administration-shorter tools written in plain language are often more appropriate for many older people ${ }^{76}$; whether or not instruments have been psychometrically tested; and evidence of instrument appropriateness for use with targeted aged care populations. Amenability to economic evaluation and instrument alignment with policy objectives of state and national governments may also influence decisions around instrument suitability, particularly when selecting instruments for quality assurance and indicator purposes.

No single instrument stood out unequivocally as best suited for use in aged care settings. The suitability of instruments, particularly those designed for specific aged care populations such as adults living with dementia, will vary across aged care contexts and populations and the aims or goals of instrument administration. Moreover, we noticed a positive correlation between QoL domain coverage and the number of instrument items, suggesting that ideals of instrument comprehensiveness trade-off against ideals of instrument simplicity and ease of use. For example, while the SF series and EQ-5D instruments are readily available and are logistically feasible for use in aged care settings, they do not adequately capture aspects of life quality which are often important to older people (ie, existential and spiritual matters ${ }^{24}{ }^{77}$ ) and only partially emulate outcomes reflective of the current aims of aged care services in Australia ${ }^{78}$ and other OECD nations. Furthermore, instruments that capture a multidimensional profile can be very useful in specific circumstances, for example for intervention trials where detailed information on individual QoL domains may be required. However, there are situations in which a profile is less useful, and a single index is required. This is especially so in evaluative studies, for example, in assessing cost-effectiveness.

Other instruments, such as the ASCOT and ICECAP-O, designed to capture aspects of QoL important to older people, were less frequently used, have been less psychometrically validated ${ }^{69}$ but may be more suited to Australia's aged care context. The ASCOT and ICECAP-O have been designed in mind for European policy objectives-namely to establish methods of capturing the effectiveness and quality of social care services for older adults $^{75}$ - which are analogous to current policy objectives in Australia. Both instruments have been elsewhere endorsed by some organisations ${ }^{49}$ for use for performance monitoring in Australia, although use alongside the SF series and the EQ-5D may be warranted as neither the ASCOT or ICECAP-O consider physical and mental health domains. Nonetheless, being conceptually focused, the ASCOT and ICECAP-O are better equipped to facilitate a more targeted assessment and are amenable to economic analysis. ${ }^{80}$

Adults living with dementia make up 53\% of residential care clients in Australia, $48 \%$ in the USA, and $69 \%$ in the UK. ${ }^{6}$ There is a fundamental need to determine and capture what is important to aged care clients living with dementia to form a coherent basis for guiding quality improvement and policy decisions. ${ }^{6}$ Of dementia-specific instruments identified in this review, the QoL-AD was the most widely used, although elsewhere this instrument has been found less psychometrically sound compared with other dementia-specific instruments such as the Dementia Quality of Life (DEMQOL) ${ }^{81}$ However, compared with the QoL-AD, we found other dementia-specific instruments to be more exclusively health-orientated and to cover fewer domains. The QoL-AD may be suitable for use in the Australian aged care context as it is currently capable of supporting economic analysis of care services ${ }^{82}$ alongside the DEMQOL ${ }^{83}$ and non-dementia-specific measures (ASCOT, ICECAP, EQ-5D ${ }^{69}$ ).

Evidently, consideration of a multitude of factors is necessary for the meaningful collection of QoL outcomes in aged care. It is also evident that no single instrument will be suitable for use for aged care clients generally. As has already been suggested by the Council on the Ageing, should the collection of QoL outcomes be mandated in Australia, given the heterogeneity of aged care settings and clients, inclusions of QoL metrics should allow providers a degree of flexibility to apply instruments relevant to aged care clients in question. ${ }^{36}$ Effective collection will require instruments which are embedded with person-centred content, are phrased and administered using culturally sensitive and age-appropriate language, and which allow for economic evaluation and comparison between providers. ${ }^{784}$ Developments in this space are, however, encouraging, with recent studies identifying leading QoL dimensions relevant to older people receiving aged care services $^{7}$ to support economic evaluation. ${ }^{85}$

\section{Strengths and limitations}

We limited the inclusion criteria to instruments used for older adults receiving aged care services. This decision was justified on pragmatic grounds in order to keep the review more focused on measures for use with older adults; extensive literature and inconsistent phrasing remain significant challenges for those conducting systematic reviews on the topic of QoL. It is unlikely that any search strategy could collate a definitive list of instruments; however, the approach taken in the current work is able to complement the selective reviews already in existence. In contrast to the psychometric focus of previous reviews, ${ }^{20} 70$ our objective was to inform researchers and care providers about the domains available, the thematic differences among instruments, and their use within aged care. While we have provided a preliminary overview of the psychometric properties of the included instruments to further guide instrument choice and use, collatable evidence relating to psychometric properties of many 
instruments used in aged care homes has been systematically and comprehensively reviewed elsewhere. ${ }^{20}$ Further research should investigate the psychometric properties of this wider set of instruments, with a specific focus on content and construct validity. Merging these strands of work should strengthen the methodological quality and our understanding of the subject.

\section{Implications}

Our work identifies current QoL instruments used in aged care settings internationally. It represents a first step in supporting choice of suitable instruments to be used for monitoring and evaluating quality of care in aged care service settings. Implementation of regular measurement of QoL in aged care and publication of such information will likely encourage more comprehensive benchmarking for organisations and service providers. Ability to examine benchmarks and trends over time may also enable aged care consumers and their families to make evidence-based decisions that are personally relevant, needs-specific and to support maintenance of QoL as they age. Although some aged care providers in Australia have incorporated QoL instruments to track quality of care on their own initiative, ${ }^{4}$ no providers currently publicise $\mathrm{QoL}$ outcomes to inform consumer choice. Notwithstanding, evidence demonstrates QoL instruments are reliable, used and readily accepted by care staff and can lead to an enhanced understanding of older adults' needs. ${ }^{86} 87$

\section{Conclusion}

Ultimately, tracking the physical, emotional, social and existential needs of older people requires standardised measurement and valuation of QoL measures that are applicable across the aged care sector. Our comprehensive overview of available instruments, their characteristics and use in aged care settings, provides an important resource for governments, aged care services and the aged care workforce. The evidence we created may support decision-making when choosing QoL measures for research and for care quality monitoring in aged care. The wide variety of QoL instruments identified in our review serves as an important reminder that the choice of the most appropriate instrument will depend on the domains of interest, psychometric properties and feasibility of administration in various aged care contexts.

\footnotetext{
Author affiliations

${ }^{1}$ Centre for Health Systems and Safety Research, Australian Institute of Health Innovation, Macquarie University, Sydney, New South Wales, Australia

${ }^{2}$ Centre for Ageing, Cognition and Wellbeing, Macquarie University, Sydney, New South Wales, Australia

${ }^{3}$ NHMRC Partnership Centre for Health Systems Sustainability, Macquarie University, Sydney, New South Wales, Australia

${ }^{4}$ Health and Social Care Economics Group, Caring Futures Institute, Flinders University of South Australia, Adelaide, South Australia, Australia
}

\section{Twitter Yvonne Zurynski @YvonneZurynski}

Acknowledgements We would like to thank the authors of the original studies for their contribution to our systematic review, especially those authors who provided their instrument for the analysis.
Contributors JS developed the research design, analysed the data, interpreted the results, has primary responsibility for the final content and is acting as guarantor. GTK and LD analysed the data and interpreted the results. JS and GTK drafted manuscript. YZ, JW and JR critically reviewed the manuscript. All authors approved the manuscript.

Funding The authors have not declared a specific grant for this research from any funding agency in the public, commercial or not-for-profit sectors.

Competing interests None declared.

Patient consent for publication Not applicable.

Provenance and peer review Not commissioned; externally peer reviewed.

Data availability statement Data are available on reasonable request. Data are available upon reasonable request. The data are available upon request from the corresponding author (joyce.siette@mq.edu.au).

Supplemental material This content has been supplied by the author(s). It has not been vetted by BMJ Publishing Group Limited (BMJ) and may not have been peer-reviewed. Any opinions or recommendations discussed are solely those of the author(s) and are not endorsed by BMJ. BMJ disclaims all liability and responsibility arising from any reliance placed on the content. Where the content includes any translated material, BMJ does not warrant the accuracy and reliability of the translations (including but not limited to local regulations, clinical guidelines, terminology, drug names and drug dosages), and is not responsible for any error and/or omissions arising from translation and adaptation or otherwise.

Open access This is an open access article distributed in accordance with the Creative Commons Attribution Non Commercial (CC BY-NC 4.0) license, which permits others to distribute, remix, adapt, build upon this work non-commercially, and license their derivative works on different terms, provided the original work is properly cited, appropriate credit is given, any changes made indicated, and the use is non-commercial. See: http://creativecommons.org/licenses/by-nc/4.0/.

ORCID iDs

Joyce Siette http://orcid.org/0000-0001-9568-5847

Gilbert Thomas Knaggs http://orcid.org/0000-0003-4710-6104

Yvonne Zurynski http://orcid.org/0000-0001-7744-8717

Julie Ratcliffe http://orcid.org/0000-0001-7365-1988

\section{REFERENCES}

1 House of Commons and Health Committee. Accountability Hearing with the Care Quality Commission: Government and Care Quality Commission Responses to the Committee's Seventh Report of Session 2012-13. London, 2013.

2 Malley J, Holder J, Dodgson R, et al. Regulating the quality and safety of long-term care in England, in regulating long-term care quality: an international comparison. New York: Cambridge University Press, 2014: 180-210.

3 Kumpunen S, Trigg L, Holder J. Helping older people to use quality information to choose residential care. JLTC 2019:87-98.

4 Council of the Ageing (COTA) and C. Irlam, measuring quality and consumer choice in aged care. Canberra, 2018.

5 Theofilou P. Quality of life: definition and measurement. Eur J Soc Psychol 2013;9:150-62.

6 OECD and E. Union. A good life in old age? Paris: OECD Publishing, 2013.

7 Cleland J, Hutchinson C, McBain C, et al. Developing dimensions for a new preference-based quality of life instrument for older people receiving aged care services in the community. Qual Life Res 2021;30:555-65.

8 Feeny D. Preference-based measures: utility and quality-adjusted life years, in assessing quality of life in clinical trials. New York: Oxford University Press, 2005: 405-31.

9 Hennessy $\mathrm{CH}$, Moriarty DG, Zack MM, et al. Measuring healthrelated quality of life for public health surveillance. Public Health Rep 1994;109:665.

10 Meagher G, Cortis N, Charlesworth S, et al. Meeting the social and emotional support needs of older people using aged care services. Sydney: Macquarie University, UNSW Sydney and RMIT University, 2019.

11 Gallant NL, Peckham A, Marchildon G, et al. Provincial legislative and regulatory standards for pain assessment and management in long-term care homes: a scoping review and in-depth case analysis. BMC Geriatr 2020;20:1-14. 
12 The Registry of Senior Australians (ROSA). International and national quality and safety indicators for aged care. Report for the Royal Commission into aged care quality and safety, 2020.

13 Jeon Y-H, Casey A-N, Vo K, et al. Associations between clinical indicators of quality and aged-care residents' needs and consumer and staff satisfaction: the first Australian study. Aust Health Rev 2019;43:133-41.

14 OECD. United Kingdom: highlights from a good life in old age? monitoring and improving quality in long-term care. Paris: OECD Publishing, 2013.

15 Netten A, Burge P, Malley J, et al. Outcomes of social care for adults: developing a preference-weighted measure. Health Technol Assess 2012;16:1-166.

16 Aged Care Quality and Safety Commission,. Guidance and resources for providers to support the aged care quality Standards, 2019.

17 The Royal Commission into Aged Care Quality and Safety,. Royal Commission into aged care quality and safety final report. Canberra, 2021.

18 Tracey R, Briggs L. Royal commission into aged care quality and safety: interim report: neglect. Canberra: The Royal Commission into Aged Care Quality and Safety, 2019.

19 Cooke PJ, Melchert TP, Connor K. Measuring well-being: a review of instruments. Couns Psychol 2016;44:730-57.

20 Aspden T, Bradshaw SA, Playford ED, et al. Quality-Of-Life measures for use within care homes: a systematic review of their measurement properties. Age Ageing 2014;43:596-603.

21 Linton M-J, Dieppe P, Medina-Lara A. Review of 99 selfreport measures for assessing well-being in adults: exploring dimensions of well-being and developments over time. BMJ Open 2016;6:e010641.

22 Schiaffino KMOther. Other measures of psychological well-being: the affect balance scale (ABS), general health questionnaire (GHQ12), life satisfaction Index-A (LSI-A), Rosenberg self-esteem scale, satisfaction with life scale (SWLS), and State-Trait anxiety index (STAI). Arthritis Rheum 2003;49:S165-74.

23 Braun V, Clarke V. Using thematic analysis in psychology. Qual Res Psychol 2006;3:77-101.

24 van Leeuwen KM, van Loon MS, van Nes FA, et al. What does quality of life mean to older adults? A thematic synthesis. PLoS One 2019;14): :e0213263.

25 Rabins PV, Kasper JD. Measuring quality of life in dementia: conceptual and practical issues. Alzheimer Dis Assoc Disord 1997;11 Suppl 6:100-4.

26 Richardson J, Sinha K, lezzi A, et al. Modelling utility weights for the Assessment of Quality of Life (AQoL)-8D. Qual Life Res 2014;23): :2395-404.

27 Sintonen H. The 15-D Measure of Health Related Quality of Life: Reliability, Validity and Sensitivity of its Health State Descriptive System. Working Paper 41, 1994.

28 Cummins RA. Comprehensive quality of life scale-Intellectual/ cognitive disability. School of Psychology: Deakin University, 1997.

29 Smith S, Lamping D, Banerjee S, et al. Measurement of healthrelated quality of life for people with dementia: development of a new instrument (DEMQOL) and an evaluation of current methodology. Health Technol Assess 2005;9:1iii-93.

30 Parkerson GR, Broadhead WE, Tse CK. The Duke health profile. A 17-item measure of health and dysfunction. Med Care 1990;28:1056-72.

31 Brod M, Stewart AL, Sands L, et al. Conceptualization and measurement of quality of life in dementia: the dementia quality of life instrument (DQoL). Gerontologist 1999;39:25-36.

32 EuroQol Group. EuroQol--a new facility for the measurement of health-related quality of life. Health Policy 1990;16:199-208.

33 Torrance GW, Feeny DH, Furlong WJ, et al. Multiattribute utility function for a comprehensive health status classification system. health Utilities index mark 2. Med Care 1996;34:702-22.

34 Coast J, Flynn TN, Natarajan L, et al. Valuing the icecap capability index for older people. Soc Sci Med 2008;67:874-82.

35 Haugan G, Rinnan E, Espnes GA, et al. Development and psychometric properties of the Joy-of-Life scale in cognitively intact nursing home patients. Scand J Caring Sci 2019;33:801-14.

36 Priebe S, Huxley P, Knight S, et al. Application and results of the Manchester short assessment of quality of life (Mansa). Int J Soc Psychiatry 1999;45:7-12.

37 Slade GD, Spencer AJ. Development and evaluation of the oral health impact profile. Community Dent Health 1994;11:3-11.

38 Bowling A, Banister D, Sutton S, et al. A multidimensional model of the quality of life in older age. Aging Ment Health 2002;6:355-71.
39 Bowling A, Gabriel Z. An Integrational model of quality of life in older age. results from the ESRC/MRC HSRC quality of life survey in Britain. Soc Indic Res 2004;69:1-36.

40 Bowling A. Ageing well: quality of life in old age. Bowling, a. (2005) ageing well: quality of life in old age. Open University Press, Maidenhead, UK, 2005.

41 Lawton MP. The Philadelphia geriatric center morale scale: a revision. J Gerontol 1975;30:85-9.

42 Logsdon RG, Gibbons LE, Mccurry SM, et al. Quality of life in Alzheimer's disease: Patient and caregiver reports. Journal of Mental Health and Aging 1999;5:21-32.

43 Ettema TP, Dröes R-M, de Lange J, et al. QUALIDEM: development and evaluation of a dementia specific quality of life instrument-validation. Int J Geriatr Psychiatry 2007;22:424-30.

44 Ware JE, Sherbourne CD. The mos 36 -item short-form health survey (SF-36). I. conceptual framework and item selection. Med Care 1992;30:473-83.

45 World Health Organization, WHOQOL user manual. Division of mental health and prevention of substance abuse: World Health organization, 2012.

46 World Health Organization. Constitution of the world Health organization. WHO: Geneva, 1946.

47 Nussbaum M. Capabilities as fundamental entitlements: SEN and social justice. Fem Econ 2003;9:33-59.

48 Robeyns I. Sen's capability approach and gender inequality: Selecting relevant capabilities. Fem Econ 2003;9:61-92.

49 Robeyns I. The capability approach: a theoretical survey. J Human Dev 2005;6:93-117.

50 Sen A. Choice, welfare and measurement. Oxford: Basil Blackwell, 1982.

51 Sen A. Capability and Well-Being, in the quality of life. Oxford: Oxford University Press, 1993

52 Antonovsky A. Unraveling the mystery of health: how people manage stress and stay well. San Francisco, CA, US: Jossey-Bass, 1987: 218.

53 Keyes CLM. Promoting and protecting mental health as flourishing: a complementary strategy for improving national mental health. Am Psychol 2007;62:95-108.

54 Keyes C. Mental health as a complete state: how the salutogenic perspective completes the picture, in bridging occupational, organizational and public health. Netherlands: Springer, 2014: 179-92.

55 Keyes CLM, Westerhof GJ. Chronological and subjective age differences in flourishing mental health and major depressive episode. Aging Ment Health 2012;16:67-74.

56 Seligman ME. Flourish: a visionary new understanding of Happiness and well-being. Simon and Schuster, 2012.

57 Lehman AF. A quality of life interview for the chronically mentally ill. Eval Program Plann 1988;11:51-62.

58 Calman KC. Quality of life in cancer patients--an hypothesis. J Med Ethics 1984;10:124-7.

59 Garratt A, Schmidt L, Mackintosh A, et al. Quality of life measurement: bibliographic study of patient assessed health outcome measures. BMJ 2002;324:1417.

60 Sprangers MA, Schwartz CE. Integrating response shift into healthrelated quality of life research: a theoretical model. Soc Sci Med 1999;48): :1507-15

61 Finnema E, Dröes RM, Ribbe M, et al. A review of psychosocial models in psychogeriatrics: implications for care and research. Alzheimer Dis Assoc Disord 2000;14:68-80.

62 Dröes R-M, Boelens-Van Der Knoop ECC, Bos J, et al. Quality of life in dementia in perspective. Dementia 2006;5:533-58.

63 Kitwood T, Bredin K. Towards a theory of dementia care: personhood and well-being. Ageing Soc 1992;12: :269-87.

64 Lawton M. A multidimensional view of quality of life in frail elders, in the concept and measurement of quality of life in the frail elderly. San Diego, CA: Academic Press, 1991: 3-23.

65 Locker D. Measuring oral health: a conceptual framework. Community Dent Health 1988;5:3-18.

66 World Health Organization,. International classification of impairments, disabilities, and handicaps : a manual of classification relating to the consequences of disease, published in accordance with resolution WHA29.35 of the Twenty-ninth World Health Assembly, May 1976. World Health Organization: Geneva, 1980.

67 Boyle MH, Torrance GW, Sinclair JC, et al. Economic evaluation of neonatal intensive care of very-low-birth-weight infants. $N$ Engl $J$ Med 1983;308:1330-7.

68 Amsterdam Public Health. Guideline for systematic reviews of outcome measurement instruments, 2021. Available: https://www. cosmin.nl/tools/guideline-conducting-systematic-review-outcomemeasures/?portfolioCats $=19$ 
69 Bulamu NB, Kaambwa B, Ratcliffe J. A systematic review of instruments for measuring outcomes in economic evaluation within aged care. Health Qual Life Outcomes 2015;13:179.

70 Hughes LJ, Farina N, Page TE, et al. Psychometric properties and feasibility of use of dementia specific quality of life instruments for use in care settings: a systematic review. Int Psychogeriatr 2021;33:917-31.

71 Haywood KL, Brett J, Tutton E, et al. Patient-Reported outcome measures in older people with hip fracture: a systematic review of quality and acceptability. Qual Life Res 2017;26:799-812.

72 Cleland J, Hutchinson C, Khadka J, et al. A review of the development and application of generic Preference-Based instruments with the older population. Appl Health Econ Health Policy 2019;17:781-801.

73 Bulamu NB, Kaambwa B, Ratcliffe J. A systematic review of instruments for measuring outcomes in economic evaluation within aged care. Health Qual Life Outcomes 2015;13:1-23.

74 Department of Health,. Transparency in outcomes: a framework for quality in adult social care: the 2012/13 adult social care outcomes framework. Leeds, 2012.

75 Grewal I, Lewis J, Flynn T, et al. Developing attributes for a generic quality of life measure for older people: preferences or capabilities? Soc Sci Med 2006;62:1891-901.

76 Bowling A, Hankins M, Windle G, et al. A short measure of quality of life in older age: the performance of the brief older people's quality of life questionnaire (OPQOL-brief). Arch Gerontol Geriatr 2013;56:181-7.

77 Brownie S, Horstmanshof L. Creating the conditions for selffulfilment for aged care residents. Nurs Ethics 2012;19:777-86.

78 Baxter R, Sandman P-O, Björk S, et al. Illuminating meanings of thriving for persons living in nursing homes. Gerontologist 2020;60:859-67.

79 Leading Aged Services Australia. Lasa taking the lead on quality indicators, 2019. Available: https://lasa.asn.au/wp-content/uploads/ 2019/10/LASA-taking-the-lead-on-quality-indicators.pdf

80 van Leeuwen KM, Bosmans JE, Jansen APD, et al. Comparing measurement properties of the EQ-5D-3L, ICECAP-O, and Ascot in frail older adults. Value Health 2015;18:35-43.

81 Chua K-C, Brown A, Little R, et al. Quality-Of-Life assessment in dementia: the use of DEMQOL and DEMQOL-Proxy total scores. Qual Life Res 2016;25:3107-18.

82 Comans TA, Nguyen K-H, Ratcliffe J, et al. Valuing the AD-5D dementia utility instrument: an estimation of a general population tariff. Pharmacoeconomics 2020;38:871-81.

83 Mulhern B, Rowen D, Brazier J, et al. Development of DEMQOL-U and DEMQOL-PROXY-U: generation of preference-based indices from DEMQOL and DEMQOL-PROXY for use in economic evaluation. Health Technol Assess 2013;17:1-140.

84 Smith Ket al. Good spirit, good life: a quality of life tool and framework for older Aboriginal peoples. Gerontologist, 2020.

85 Ratcliffe J, Cameron I, Lancsar E, et al. Developing a new quality of life instrument with older people for economic evaluation in aged care: study protocol. BMJ Open 2019;9:e028647.

86 Siette J, Georgiou A, Jorgensen M, et al. Integrating social engagement instruments into Australian community aged care assessments to enhance service provision. Health Soc Care Community 2018;26:810-8.

87 Cardona B, Fine M, Stebbing A, et al. Measuring consumer outcomes: development and testing of the Australian community care outcomes measure. Australas J Ageing 2017;36:69-71.

88 Sintonen $\mathrm{H}$. The 15D instrument of health-related quality of life: properties and applications. Ann Med 2001;33:328-36.

89 Rabins PV, Kasper JD, Kleinman L, et al. Concepts and methods in the development of the ADRQL: An instrument for assessing healthrelated quality of life in persons with Alzheimer's Disease. Journal of Mental Health and Aging 1999:5:33-48.

90 Richardson J, lezzi A, Khan MA, et al. Validity and reliability of the Assessment of Quality of Life (AQoL)-8D multi-attribute utility instrument. Patient 2014;7:85-96.

91 Hawthorne G, Richardson J, Osborne R. The assessment of quality of life (AQoL) instrument: a psychometric measure of health-related quality of life. Qual Life Res 1999;8:209-24.

92 Richardson Jet al. Modelling the utility of health states with the assessment of quality of life (AQOL) $8 D$ instrument: overview and utility scoring algorithm. Victoria, Australia: Centre for Health Economics, Monash University, 2011.

93 Nocon A, Qureshi H. Outcomes of community care for users and carers: A social services perspective. Vol. 3. Portland, Or: Taylor \& Francis, 1996.
94 Nocon A, Qureshi H, Thornton P. Outcomes in community care practice. The perspectives of users' and carers' organisations. Vol. 4. University of York: Social Policy Research Unit, 1997.

95 Qureshi Het al. Outcomes in community care practice. Outcomes of social care for older people and carers. Vol. 5. University of York: Social Policy Research Unit, 1998.

96 Bamford Cet al. Outcomes in community care practice. Outcomes for disabled people and carers. Vol. 6. University of York: Social Policy Research unit, 1999.

97 Department of Health and Social Care. Adult social care outcomes framework: Handbook of definitions, 2017. Available: https:// assets.publishing.service.gov.uk/government/uploads/system/ uploads/attachment_data/file/629812/ASCOF_handbook_ definitions.pdf

98 Malley JN, Towers A-M, Netten AP, et al. An assessment of the construct validity of the Ascot measure of social care-related quality of life with older people. Health Qual Life Outcomes 2012;10:21.

99 Volicer L, Hurley AC, Blasi ZV. Scales for evaluation of end-of-life care in dementia. Alzheimer Dis Assoc Disord 2001:15:194-200.

100 van Soest-Poortvliet MC, van der Steen JT, Zimmerman S, et al. Psychometric properties of instruments to measure the quality of end-of-life care and dying for long-term care residents with dementia. Qual Life Res 2012;21:671-84.

101 Gullone E, Cummins RA. The comprehensive quality of life scale: a psychometric evaluation with an adolescent sample. Behaviour Change 1999;16:127-39.

102 Cummins RA, Mccabe MP, Romeo Y, et al. Validity studies the comprehensive quality of life scale (Comqol): instrument development and psychometric evaluation on College staff and students. Educ Psychol Meas 1994;54:372-82.

103 Lawton MP. Environment and other determinants of well-being in older people. Gerontologist 1983;23:349-57.

104 Lawton MP. Quality of life in Alzheimer disease. Alzheimer Dis Assoc Disord 1994:8 Suppl 3: :138-50.

105 Wilson IB, Cleary PD. Linking clinical variables with health-related quality of life. A conceptual model of patient outcomes. JAMA 1995;273:59-65.

106 Rapin A, Dramé M, Jolly D. Psychometric properties of the Duke health profile in a neuromuscular disease population. Eur J Phys Rehabil Med 2016;52:57-64.

107 Parkerson GR, Willke RJ, Hays RD. An international comparison of the reliability and responsiveness of the Duke health profile for measuring health-related quality of life of patients treated with alprostadil for erectile dysfunction. Med Care 1999;37:56-67.

108 Krueger R. Group dynamics and focus groups. In: Quality of life and pnarmacoeconomics in clinical trials. New York: Lippencott-Raven, 1996: 397-402.

109 Devlin NJ, Brooks R. EQ-5D and the EuroQol group: past, present and future. Appl Health Econ Health Policy 2017;15:127-37.

110 Feng Y-S, Kohlmann T, Janssen MF, et al. Psychometric properties of the EQ-5D-5L: a systematic review of the literature. Qual Life Res 2021;30:647-73.

111 von Neumann J, Morgenstern O, Rubinstein A. Theory of games and economic behavior (60th anniversary Commemorative edition. Princeton University Press, 1944.

112 Saiguay W, Sakthong P. The psychometric testing of the Thai version of the health Utilities index in patients with ischemic heart disease. Qual Life Res 2013;22:1753-9.

113 Mpundu-Kaambwa C, Chen G, Huynh E, et al. A review of preference-based measures for the assessment of quality of life in children and adolescents with cerebral palsy. Qual Life Res 2018;27:1781-99.

114 Guyatt G, Walter S, Norman G. Measuring change over time: assessing the usefulness of evaluative instruments. $J$ Chronic Dis 1987;40:171-8.

115 Hirdes JP, Ljunggren G, Morris JN, et al. Reliability of the interRAI suite of assessment instruments: a 12-country study of an integrated health information system. BMC Health Serv Res 2008;8:277.

116 Mor V, Finne-Soveri H, Hirdes JP, et al. Long term care quality monitoring using the interRAl common clinical assessment language, in Performance measurement for health system improvement : experiences, challenges and prospects. Cambridge: Cambridge University Press, 2010: 472-505.

$117 \mathrm{Kim} \mathrm{H}$, Jung $\mathrm{Y}-\mathrm{I}$, Sung $\mathrm{M}$, et al. Reliability of the interRAI long term care facilities (LTCF) and interRAI home care (HC). Geriatr Gerontol Int 2015;15:220-8.

118 Hirdes JP, van Everdingen C, Ferris J, et al. The interRAl suite of mental health assessment instruments: an integrated system for the continuum of care. Front Psychiatry 2019;10:926. 
119 Haugan G, Rinnan E, Espnes GA, et al. Development and psychometric properties of the Joy-of-Life scale in cognitively intact nursing home patients. Scand J Caring Sci 2019;33:801-14.

120 Eklund M, Sandqvist G. Psychometric properties of the satisfaction with daily occupations (SDO) instrument and the Manchester short assessment of quality of life (MANSA) in women with scleroderma and without known illness. Scand J Occup Ther 2006;13:23-30.

121 Petkari E, Giacco D, Priebe S. Factorial structure of the Manchester short assessment of quality of life in patients with schizophreniaspectrum disorders. Qual Life Res 2020;29:833-41.

122 Hunt SM, McKenna SP, McEwen J, et al. A quantitative approach to perceived health status: a validation study. J Epidemiol Community Health 1980;34:281-6.

123 Hinz A, Klaiberg A, Schumacher J, et al. [The psychometric quality of the Nottingham Health Profile (NHP) in the general population]. Psychother Psychosom Med Psychol 2003;53:353-8.

124 Sharples LD, Todd CJ, Caine N, et al. Measurement properties of the Nottingham health profile and short form 36 health status measures in a population sample of elderly people living at home: results from ELPHS. Br J Health Psychol 2000;5:217-33.

125 Wiklund I, Romanus B, Hunt SM. Self-assessed disability in patients with arthrosis of the hip joint. reliability of the Swedish version of the Nottingham health profile. Int Disabil Stud 1988;10:159-63.

126 Carlsson E, Olsson SB, Hertervig E. The role of the nurse in enhancing quality of life in patients with an implantable cardioverterdefibrillator: the Swedish experience. Prog Cardiovasc Nurs 2002;17:18-25.

127 Kjeldsen BJ, Thorsen H, Whalley D, et al. Influence of follow-up on health-related quality of life after radical surgery for colorectal cancer. Scand J Gastroenterol 1999;34:509-15.

128 Klevsgård R, Hallberg IR, Risberg B, et al. The effects of successful intervention on quality of life in patients with varying degrees of lower-limb ischaemia. Eur J Vasc Endovasc Surg 2000;19:238-45.

129 Klevsgård R, Risberg BO, Thomsen MB, et al. A 1-year followup quality of life study after hemodynamically successful or unsuccessful surgical revascularization of lower limb ischemia. $J$ Vasc Surg 2001;33:114-22.

130 Dreer LE, McGwin G, Scilley K, et al. Development of a nursing home vision-targeted health-related quality of life questionnaire for older adults. Aging Ment Health 2007;11:722-33.

131 Owsley C, McGwin G, Scilley K, et al. Impact of cataract surgery on health-related quality of life in nursing home residents. $\mathrm{Br} \mathrm{J}$ Ophthalmol 2007;91:1359-63.

132 Owsley C, McGwin G, Scilley K, et al. Effect of refractive error correction on health-related quality of life and depression in older nursing home residents. Arch Ophthalmol 2007;125:1471-7.

133 Zucoloto ML, Maroco J, Campos JADB. Psychometric properties of the oral health impact profile and new methodological approach. $J$ Dent Res 2014;93:645-50.

134 Garratt AM, Ruta DA. The patient generated index. In: Joyce CRB, O'Boyle CA, McGee H, eds. Individual quality of life approaches to conceptualisation and assessment. Amsterdam: Harwood Academic Publishers, 1999

135 Bowling A. The psychometric properties of the Older People's Quality Of Life questionnaire, compared with the CASP-19 and the WHOQOL-OLD. Current Gerontology and Geriatrics Research, 2009.

136 Haugan G. Meaning-in-life in nursing-home patients: a correlate with physical and emotional symptoms. J Clin Nurs 2014;23:1030-43.

137 Wong E, Woo J, Hui E, et al. Examination of the Philadelphia geriatric morale scale as a subjective quality-of-life measure in elderly Hong Kong Chinese. Gerontologist 2004;44:408-17.

138 Pinar $\mathrm{R}, \mathrm{Oz} \mathrm{H}$. Validity and reliability of the Philadelphia geriatric center morale scale among Turkish elderly people. Qual Life Res 2011;20:9-18.
139 Niklasson J, Conradsson M, Hörnsten C, et al. Psychometric properties and feasibility of the Swedish version of the Philadelphia geriatric center morale scale. Qual Life Res 2015;24:2795-805.

140 McDonald T. Measurement features of a long-term care quality of life (LTC-QoL) assessment scale. J Care Serv Manag 2013;7:76-86.

141 McDonald T, Russell F. Long-Term care quality-of-life scale utility in community home care. Nurs Health Sci 2019;21:494-500.

142 McDonald T. Measurement features of a long-term care quality of life (LTC-QoL) assessment scale. J Care Serv Manag 2020;7:76-86

143 Weiner DK, Hanlon JT. Pain in nursing home residents: management strategies. Drugs Aging 2001;18:13-29.

144 Butterworth P, Crosier T. The validity of the SF-36 in an Australian National household survey: demonstrating the applicability of the household income and labour dynamics in Australia (HILDA) survey to examination of health inequalities. BMC Public Health 2004;4:44.

145 Bunevicius A. Reliability and validity of the SF-36 health survey questionnaire in patients with brain tumors: a cross-sectional study. Health Qual Life Outcomes 2017;15:92.

146 LoMartire R, Äng BO, Gerdle B, et al. Psychometric properties of short Form-36 health survey, EuroQol 5-dimensions, and hospital anxiety and depression scale in patients with chronic pain. Pain 2020;161:83-95.

147 Gandek B, Sinclair SJ, Kosinski M, et al. Psychometric evaluation of the SF-36 health survey in Medicare managed care. Health Care Financ Rev 2004;25:5-25.

148 Cameron JI, Herridge MS, Tansey CM, et al. Well-Being in informal caregivers of survivors of acute respiratory distress syndrome. Crit Care Med 2006;34:81-6.

149 Supino PG, Borer JS, Franciosa JA, et al. Acceptability and psychometric properties of the Minnesota living with heart failure questionnaire among patients undergoing heart valve surgery: validation and comparison with SF-36. J Card Fail 2009;15:267-77.

150 Wittink H, Turk DC, Carr DB, et al. Comparison of the redundancy, reliability, and responsiveness to change among SF-36, Oswestry disability index, and multidimensional pain inventory. Clin J Pain 2004;20:133-42.

151 Haywood KL, Garratt AM, Fitzpatrick R. Quality of life in older people: a structured review of generic self-assessed health instruments. Qual Life Res 2005;14:1651-68.

152 Diener E, Emmons RA, Larsen RJ, et al. The satisfaction with life scale. J Pers Assess 1985;49:71-5.

153 López-Ortega M, Torres-Castro S, Rosas-Carrasco O. Psychometric properties of the satisfaction with life scale (SWLS): secondary analysis of the Mexican health and aging study. Health Qual Life Outcomes 2016;14:170.

154 Swami V, Chamorro-Premuzic T. Psychometric evaluation of the Malay satisfaction with life scale. Soc Indic Res 2009;92:25-33.

155 Caballero FF, Miret M, Power M, et al. Validation of an instrument to evaluate quality of life in the aging population: WHOQOL-AGE. Health Qual Life Outcomes 2013;11:177.

156 Santos D, Abad FJ, Miret M, et al. Measurement invariance of the WHOQOL-AGE questionnaire across three European countries. Qual Life Res 2018;27:1015-25.

157 Skevington SM, Lotfy M, O'Connell KA, et al. The world Health organization's WHOQOL-BREF quality of life assessment: psychometric properties and results of the International field trial. A report from the WHOQOL group. Qual Life Res 2004;13:299-310.

158 von Steinbüchel N, Lischetzke T, Gurny M, et al. Assessing quality of life in older people: psychometric properties of the WHOQOLBREF. Eur J Ageing 2006;3:116-22.

159 Skevington SM, Epton T. How will the sustainable development goals deliver changes in well-being? A systematic review and metaanalysis to investigate whether WHOQOL-BREF scores respond to change. BMJ Glob Health 2018;3:e000609. 